\title{
Fetomaternal Outcome in Pregnant Women with Acute Hepatitis E
}

\author{
Sadia Asghar ${ }^{1, ~ *, ~ S a d i a ~ M a q b o o l ~}{ }^{2}$ \\ ${ }^{1}$ Department of Obstetrics and Gynecology, Rai Medical College, Sargodha, Pakistan \\ ${ }^{2}$ Department of Obstetrics and Gynecology, Ganga Ram Hospital, Lahore, Pakistan \\ Email address: \\ azanayan36@gmail.com (S. Asghar),sadiamaqbool2005@gmail.com (S. Maqbool) \\ ${ }^{*}$ Corresponding author
}

\section{To cite this article:}

Sadia Asghar, Sadia Maqbool. Fetomaternal Outcome in Pregnant Women with Acute Hepatitis E. Journal of Gynecology and Obstetrics. Vol. 7, No. 6, 2019, pp. 166-169. doi: 10.11648/j.jgo.20190706.13

Received: May 1, 2019; Accepted: October 21, 2019; Published: October 31, 2019

\begin{abstract}
Hepatitis E is fairly common among pregnant population and puts a threat to mother and fetal wellbeing. Only limited research is available on association of Hepatitis $E$ infection in pregnancy with feto-maternal outcome. The purpose of the current study was to investigate such patients while carefully eliminating bias by controlling confounders. We aimed to determine the feto-maternal outcome in pregnant women with acute hepatitis E. A descriptive case series was conducted to find feto-maternal outcome in pregnant women with acute hepatitis E. The mean maternal age was $30.05 \pm 4.49$ years ad mean Gestational age of the patients was $35.73 \pm 2.10$ months. Most (47\%) of the patients were para 3 followed by para $2(31.8 \%)$. $78.8 \%$ of the mothers underwent caesarean delivery. Most of the patients had Preterm delivery (69.7\%). 16 (24.2\%) patients died while majority (75.8\%) of the patients survived for more than 30 days after delivery. Most of the mothers $(50.0 \%)$ died during first 10 days of delivery. $28.8 \%$ of patients suffered fetal loss while majority $(71.2 \%)$ of the neonates survived for more than 7 days. Majority $(78.9 \%)$ of those who expired died in utero while only a smaller percentage $(21.1 \%)$ expired in neonatal period. Hepatitis E infection in pregnancy is associated with poor feto-maternal outcome. Careful monitoring and early intervention in the form of caesarean delivery can improve the outcome.
\end{abstract}

Keywords: Viral Hepatitis, Hepatitis E, Feto-Maternal Outcome

\section{Introduction}

Like other forms of viral hepatitis, Hepatitis E also puts serious threat to human health. Millions of new infection occur each year globally with more than half of infection occurring is South Asia [1]. Being largely undiagnosed the actual prevalence of hepatitis $\mathrm{E}$ infection is quite higher than anticipated prevalence of $20.2 \%$ [2]. HEV is known to have five genotype four of which have been detect in human, genotype 1 and 2 are more virulent, genotype 3 and 4 are more attenuated and accountable for subclinical infection [3]. Reasons for the difference in the outcome of HEV in different geographic areas remain unclear [4]. Hepatitis E can have variable disease course from mild flue like illness to more severe fulminate hepatic failure [5].

It has a predilection to cause severe disease in pregnant female with up to $60 \%$ developing fulminate hepatic failure and a maternal death rate up to $31 \%$ [6]. Acute hepatitis is pregnancy regardless of its subtype puts the life of mother and fetus in danger [7]. The nutritional, immunological and genetic factor play role in patho-physiology of fulminate HEV in pregnancy [8]. Viral load of HEV during pregnancy become significant high [9]. Shrestha eth al in 2011showed that HEV infection in pregnancy were associated with poor feto-maternal outcome and increase need for operative intervention [10]. Similar association have also been reported by mansoor eth al in 2011 hamid eth al in 1996 [11, 12]. During an outbreak in Sudan in 2010 to 2011 among pregnant woman with HEV infection there were 14 intrauterine death and 9 premature deliveries [13].

The purpose of this study is to study the morbidity and mortality of pregnant women with hepatitis infection.

\section{Subject and Methods}

It's a descriptive case series study conducted at 
Department of Obstetrics and Gynecology, Sir Ganga Ram Hospital Lahore for period 6 months i.e. from September 2016 to March 2017. Sample size of 66 cases was calculated by WHO manual with $80 \%$ confidence level and $7 \%$ margin of error while taking expected rate of preterm delivery to be $67 \%$ in pregnant women with Acute Hepatitis E.

Pregnant women included in the study were those with acute hepatitis E (diagnosed by the presence of Hepatitis E IgM antibodies in the sera of pregnant women) with gestational age of 32 weeks or more at presentation (on dating scan). Patients with singleton pregnancy on ultrasound. Patients with no other co-morbid condition known to be associated with adverse maternal and fetal outcome e.g. hypertensive and cardiovascular disorders, maternal diabetes etc. assessed on previous clinical record, history and examination.

Pregnant woman having liver disorders or other types of viral hepatitis evident from previous clinical record or discovered during routine work up. Patients with multiple gestations (on ultrasound). Patients with congenital fetal anomalies (on ultrasound). Informed consent was taken from the patient and data was kept anonymous for privacy the study was approved by institutional review board of the hospital.

66 patients who presented at the Department of Gynecology and Obstetrics, Sir Ganga Ram Hospital, Lahore and who fulfilled the above criteria were counseled and explained the details of the study. Written informed consent and detailed history was taken from each patient. Patients were followed weekly after presentation until 4 weeks after delivery. Mode of delivery was noted. If female would die within hospital stay, during delivery of within 4 weeks after delivery then maternal death was noted. Death of the fetus in utero or with in first 7 days of life was noted. Fetal Outcome was described in terms of pre-term Delivery (if baby delivered before 37 completed weeks of gestation) and fetal Death (death of the fetus in utero or with in first 7 days of life).

All the collected data was entered into SPSS version 23 . Numerical variables i-e maternal age, gestational age and parity were presented by mean $\pm \mathrm{SD}$ and range. Categorical variables i-e mode and term of delivery, maternal and fetal death and timing of maternal and fetal death were presented as frequency and percentage.

\section{Result}

The mean age of $30.05 \pm 4.49$ years. The mean gestational age of patients at time of presentation was $35.73 \pm 2.10$ weeks. There were $11(16.7 \%)$ primiparous and $55(83.7 \%)$ were multiparous. Table 1

Out of 66, Caesarean delivery occurred in $52(78.8 \%)$ while $14(21.2 \%)$ delivered through normal vaginal delivery. Preterm delivery occurred in $46(69.7 \%)$ while 20 (30.3\%) had full-term delivery. Maternal death occurred in 16 $(24.2 \%)$ females while fetal death occurred in $19(28.8 \%)$ neonates. In fetal death cases, $15(22.7 \%)$ had IUD while 4 $(6.1 \%)$ died within 7 days of life. Table 2.
Table 1. Baseline characteristics of patients.

\begin{tabular}{ll}
\hline Age (years) & $30.05 \pm 4.94$ \\
Gestational Age & $35.73 \pm 2.11$ \\
Primiparous & $11(16.7 \%)$ \\
Multiparous & $55(83.7 \%)$ \\
\hline
\end{tabular}

Table 2. Outcome of pregnancy.

\begin{tabular}{ll}
\hline Mode of delivery & \\
\hline SVD & $14(21.2 \%)$ \\
C-section & $52(78.8 \%)$ \\
Preterm delivery & $46(69.7 \%)$ \\
Term delivery & $20(30.3 \%)$ \\
Maternal Death & $16(24.2 \%)$ \\
Fetal Death & $19(28.8 \%)$ \\
IUD & $15(22.7 \%)$ \\
First 7 days of life & $4(6.1 \%)$ \\
\hline
\end{tabular}

\section{Discussion}

Liver abnormalities and jaundice are rare in pregnant women and are seen in about $0.3-3 \%$ of pregnancies. But when they do occur, they may portend serious liver diseases either due to pregnancy- associated acute liver diseases (e.g., preeclampsia associated liver disease, acute fatty liver disease of pregnancy and hemolysis elevated liver enzymes and low platelet syndrome (HELLP)) or an acute onset viral hepatitis (e.g., hepatitis A and hepatitis B). Acute hepatitis A and $\mathrm{E}$ are not commonly come across in industrialized countries. Since they are spread mainly via the fecal oral route, it is principally seen in evolving countries where hygiene is poor. Management rests reassuring. Hepatitis E remains to relish a bad repute as it has long been perceived to have a high occurrence and more spartan path in gravid women in some topographical areas where HEV is prevalent. At the moment, only few studies have investigated that fetomaternal outcome in pregnant women who suffer acute hepatitis E infection during pregnancy.

66 cases who met the inclusion criteria were enrolled in this study. The mean maternal age was $30.05 \pm 4.49$ years ad mean Gestational age of the patients was $35.73 \pm 2.10$ months. Most (47\%) of the patients were para 3 followed by para 2 $(31.8 \%)$ which may signify the increasing risk of hepatitis e infection with subsequent pregnancies. It was found that HEV infection was associated with Caesarean delivery (78.8\%). Simple Vaginal Delivery was possible in only $21.2 \%$ cases. Most of the patients had Preterm delivery $(69.7 \%)$. All of the SVDs were full term while only 6 $(11.5 \%)$ of the patients with C-Section were full term and Majority $(\mathrm{n}=46,88.5 \%)$ required intervention (C-Section) before term. $16(24.2 \%)$ patients died while majority $(75.8 \%)$ of the patients survived for more than 30 days after delivery. When cross tabulated maternal death with mode of delivery, only 2 patients expired among those delivered by SVD. While $14(26.9 \%)$ patients expired among those who underwent caesarean delivery. Most of the mothers (50.0\%) died during first 10 days of delivery followed by $37.5 \%$ mothers who expired somewhere between 10-20 days of delivery. When analyzed for fetal outcome, it was found that 
$28.8 \%$ of patients suffered fetal loss while majority $(71.2 \%)$ of the neonates survived for more than 7 days as shown in table 2. Majority (78.9\%) of those who expired died in utero while only a smaller percentage $(21.1 \%)$ expired in neonatal period.

The findings of previous studies investigating hepatitis $\mathrm{E}$ in pregnancy has been summarized in table 3 . It can be easily appreciated that there is a great variation among findings of different authors. However, one thing is certain and that is Hepatitis E in pregnancy is associated with poor fetomaternal outcome. The purpose of the current study was therefore to investigate this aspect of Hepatitis $\mathrm{E}$ infection while carefully eliminating the bias by controlling the confounders like concomitant other viral hepatitis, liver disease, other systemic disorders (Mansoor11, Kose14, Bassam15).

Table 3. Summary of Studies regarding Hepatitis E Infection in Pregnancy.

\begin{tabular}{|c|c|c|c|c|c|c|c|}
\hline Year & Author & Population & C-Section & Preterm Delivery & Maternal Death & IUD & Neonatal death \\
\hline 2017 & Current & Pakistan & $78.8 \%$ & $69.7 \%$ & $24.2 \%$ & $22.7 \%$ & $6.1 \%$ \\
\hline 2013 & Yasmeen 16 & Pakistan & $10 \%$ & 63.33 & $26.67 \%$ & $23.33 \%$ & $16.67 \%$ \\
\hline 2011 & Shrestha10 & India & $26 \%$ & $67 \%$ & $18 \%$ & $11.45 \%$ & $8.86 \%$ \\
\hline 2011 & *Mansoor11 & Pakistan & $66 \%$ & $76.19 \%$ & $6 \%$ & $23.80 \%$ & $23.80 \%$ \\
\hline 2013 & *Kose14 & India & $33 \%$ & $33 \%$ & N/A & $16 \%$ & N/A \\
\hline 2007 & *Bassam 15 & Iraq & $17.85 \%$ & $25 \%$ & 0 & $12.5 \%$ & $12.5 \%$ \\
\hline
\end{tabular}

Although the results of our study agree with the already existing studies yet there are significant differences. We encountered highest number of Cesareans deliveries $\mathbf{7 8 . 8 \%}$ highest among all) but it was beneficial to the patients as evident from fewer neonatal deaths (6.1\%, least among all). Similarly we did early intervention evident from higher rate of pre-term deliveries, but again, it was associated with better feto-maternal outcome evident from decreased maternal deaths $(24.2 \%$ vs. $26.67 \%)$, IUD (22.7\% vs. $23.33 \%)$ and neonatal deaths $(6.1 \%$ vs. $16.67 \%)$.

It can be thus concluded that Hepatitis $\mathrm{E}$ infection in pregnancy is associated with serious consequences in the form of increases need for surgical intervention, pre-term delivery and maternal and fetal loss. It can be however advised on the basis of our findings that careful monitoring and early intervention in the form of labor induction/ caesarean delivery in such patients may improve the outcome.

\section{Conclusion}

Acute Hepatitis E infection during pregnancy predicts poor outcome for mother, fetus, neonate. Careful monitoring and early intervention in the form of induction of labour / caesarean delivery can improve the outcome.

\section{Conflict of Interest}

Author has no conflict of interest.

\section{Acknowledgements}

Author is grateful to the women participating in the study.

\section{References}

[1] Organization WH. The global prevalence of hepatitis A virus infection and susceptibility: a systematic review. 2010.

[2] Ahmed W, Qureshi H, Arif A, Alam SE. Changing trend of viral hepatitis-"A twenty one year report from Pakistan Medical Research Council Research Centre, Jinnah
Postgraduate Medical Centre, Karachi". JPMA The Journal of the Pakistan Medical Association 2010; 60 (2): 86.

[3] Kasper L, Fauci J. Actue viral hepatitis Havrison's princ intern Med. 2015; 2 (18) 2537-2555.

[4] Lindeman ML, Gabilondo G, Romero B, et al. low prevalence of hepatitis and infection among pregnant women in Madrid spain J Med Virol. 2010; 82: 1666-1668 doi: 10.1002/jmv.201840.

[5] Purcell R, Emerson S. Hepatitis E: an emerging awareness of an old disease. Journal of hepatology 2008; 48 (3): 494-503.

[6] Alvi AH, Sabir O, IKram -ul-Haq R, Nawaz AA, Riaz: Acute hepatitits E during pregnancy; maternal and fetal Outcome professional Med. J 2015; 22 (11): 1379-1382 DoI: $10.17957 /$ TPMJ / 152748 .

[7] Navaneethan U, Al Mohajer M, Shata MT. Hepatitis E and pregnancy: understanding the pathogenesis. Liver international 2008; 28 (9): 1190-9.

[8] Rerou C, goket, locher C, moumenA T, timbely O, savany J. Prospective study of hepatis $\mathrm{E}$ virus infection among pregnant women in france. virol J 2014; 11: 11-68.

[9] Borkaoti J, Hazam R J, MOhamad A, kumar A, kar P. Does high viral load of Hepatis $E$ virus infuse the severisity and prognosis of acute level faiure during pregnancy. J Med virol. 2013 april; 85 (4); 620-6. doi: 10.1002/jmv23508. Epub 2012 Dec 26.

[10] Shrestha NS, Shrestha SK, Singh A, Malla K, Thapa LB. Maternal and perinatal outcome of pregnancy with hepatitis E infection. Journal of South Asian Federation of Obstetrics and Gynecology 2011; 3 (1): 17-20.

[11] Mansoor M, Raza H, Tariq R. Feto-maternal outcome in HEV infection. Annals of King Edward Medical University 2011; 17 (1): 86-90.

[12] Hamid SS, Jafri SW, Khan H, Shah H, Abbas Z, Fields H. Fulminant hepatic failure in pregnant women: acute fatty liver or acute viral hepatitis? Journal of hepatology 1996; 25 (1): $20-7$.

[13] Ravs D A, Juma A M, Gasim G I, K arasany M S, Adam I. An outbreak of Hepatis $\mathrm{E}$ and high maternal mortality at port sudan, eatsren sudan. pathog globe health. 2013; 107 (2): 66.8 . 
[14] Kose V, Joshi S. Pregnancy Outcome in Viral Hepatitis. Journal of South Asian Federation of Obstetrics and Gynaecology 2013; 5 (2): 60-3.

[15] Bassam AA, Ahmed Y. Outcome of Viral Hepatitis in pregnancy. J Iraq Gastroent 2007; 1 (2): 48-53.
[16] Yasmeen T, Hashmi HA, Taj A. Fetomaternal outcome with hepatitis e in pregnancy. J Coll Physicians Surg Pak 2013; 23 (10): 711-4. 